\title{
Populational genetic structure and sociogenetic structure of cocoon masses of Digelasinus diversipes (Kirby, 1882) (Hymenoptera: Symphyta: Argidae)
}

\author{
Daniele Boraschi and Marco Antonio Del Lama \\ Universidade Federal de São Carlos, Departamento de Genética e Evolução, São Carlos, SP, Brazil.
}

\begin{abstract}
Gene variation and population genetic structure of the Neotropical sawfly Digelasinus diversipes were measured by allozyme analyses using starch gel electrophoresis. Cocoon masses were collected in Eugenia glazioviana

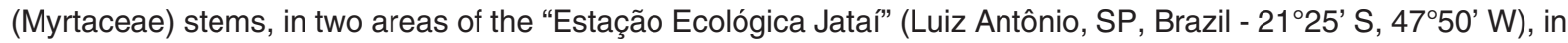
2000 and 2001. The average heterozygosity observed in this species $\left(\mathrm{H}_{\mathrm{obs}}=0.094 \pm 0.025\right)$ was not significantly different from other Symphyta groups; it was, however, significantly higher than in other Hymenoptera populations. No significant levels of inbreeding were found $\left(F_{1 S}=0.062 ; \chi^{2}=29.9 ; p>0.05\right)$, but the population was subdivided $\left(F_{S T}=0.070 ; \chi^{2}=458.9 ; p<0.05\right)$, suggesting the absence of a significant gene flow among the samples studied, due to limited dispersion ability. The low relatedness coefficients found (ranging from $0.23 \pm 0.09$ to $0.44 \pm 0.10$ ) suggest that larvae from different ovipositions associate to construct the cocoon masses.
\end{abstract}

Key words: genetic variability, population genetics, Digelasinus diversipes, Neotropical sawfly, allozymes.

Received: June 6, 2003; Accepted: April 2, 2004.

\section{Introduction}

Protein electrophoresis has been used to measure genetic variability and to verify the organization of this variation in plant and animal populations. Analyses carried out in Hymenopteran species have shown a lower polymorphism in this group than in other insects (Snyder, 1975; Metcalf et al., 1975; Pamilo et al., 1978; Lester and Selander, 1979; Berkelhamer, 1983; Graur, 1985; Crespi, 1991). The lack of heterozygosity has been explained by the sex determination system and by behavioral and ecological characteristics of the Hymenopterans (Rosenmeier and Packer, 1993). Haplodiploidy decreases the effective population size, increases the allele fixation ratio, and prevents the production of a stable polymorphism. Similarly, eusociality reduces the effective population size, since few individuals are responsible for colony reproduction $(\mathrm{Pa}-$ milo et al., 1978; Lester and Selander, 1979; Berkelhamer, 1983). In agreement with the niche-variation hypothesis (Van Valen, 1965), the more variable the environment, the higher the heterozygosity. Since in eusocial insect colonies the environment is partially buffered, lower variability is expected for these species. A lower variability is also assumed in parasitic species that may experience periodic

Send correspondence to Daniele Boraschi. Universidade Federal de São Carlos, Departamento de Genética e Evolução, Rodovia Washington Luiz km 235, 13565-905 São Carlos, SP, Brazil. E-mail: boraschidani@ zipmail.com.br. bottlenecks in population size due to changes in host abundance (Lester and Selander, 1979).

Although it is a matter of consensus that haplodiploid insects show lower genetic variability than diplodiploid insects, conflicting data about heterozygosity levels have been reported for Symphyta. This group is traditionally considered an exception in terms of genetic variation, showing values similar to diploidiploid insects (Graur, 1985; Sheppard and Heydon, 1986; Woods and Guttman, 1987; Rosenmeier and Packer, 1993; Boato and Battisti, 1996). This unexpected high genetic variation observed in Symphyta has been attributed to factors such as wide variation in the physical environment, continuous larvae feeding on plant tissues, full exposure to selection at all developmental stages, and overlapping generations (Woods and Guttman, 1987; Boato and Battisti, 1996).

Digelasinus diversipes is a sawfly species with broad distribution in the Neotropics (Smith, 1992). It is a univoltine species with larvae that are active from November through March (Penteado-Dias, 1991) and forage gregariously in Eugenia glazioviana (Myrtaceae), where cocoon masses can be found. Adults are found from October through January, and females emerge with eggs already matured. A peculiarity of sawfly larvae is their gregarious behavior, since it is in this developmental stage that these species (mainly the temperate species) cause damage. In diprionids and tenthredinids, early-instar larval groups of one posture only are common, and the late-instar larvae dis- 
perse during feeding (Craig and Mopper, 1993). However, little is known about the sociogenetic structure of this larval group, e.g., which is the mean relatedness among individuals in a cocoon mass.

Since the populational genetic structure of the Neotropical sawfly, particularly in species with gregarious larvae, is unknown, this work attempted to estimate the degree of polymorphism and the mean heterozygosity of Digelasinus diversipes, to verify its population genetic structure, and to determine the sociogenetic structure of the cocoon masses.

\section{Material and Methods}

Thirty-five cocoon masses of Digelasinus diversipes were collected in 2000 and 2001 at "Estação Ecológica Jatá'" (Luiz Antônio, SP, Brazil - 21 ${ }^{\circ} 25^{\prime}$ S, 47 $40^{\circ}$ ' W) in Eugenia glazioviana (Myrtaceae) stems located next to the lakes Pato and Infernão (samples Pat00, Pat01 and Inf01). The cocoon masses were taken from trees, identified and transported to the laboratory, where they were maintained in plastic boxes and kept wet until the end of the experiments. After emergence, adults were stored at $-20{ }^{\circ} \mathrm{C}$ until analyses. Adult specimens of $D$. diversipes were deposited at the Collection of the Department of Ecology and Evolutionary Biology of the Federal University of São Carlos (Coleção do Departamento de Ecologia e Biologia Evolutiva da Universidade Federal de São Carlos - DCBU). Extracts were made from whole adult individuals, homogenized in $0.2 \mathrm{~mL}$ of a $0.2 \%$ aqueous solution of $\beta$-mercaptoethanol and centrifuged at $2400 \mathrm{G}$ for $15 \mathrm{~min}$. at room temperature. Samples were analyzed by $14 \%$ starch gel electrophoresis (Penetrose $30^{\mathrm{TM}}$, Corn Brazil S/A), following the techniques described by Smithies (1955). Twentythree enzymatic systems were tested, corresponding to thirty-eight gene loci. The enzymatic systems and the number of corresponding loci, the buffers, and the electrophoresis conditions used are presented in Table 1 . Six adults from samples Pat00 and Inf01 and 12 adults from sample Pat01 were electrophoretically analyzed. The number of individuals analyzed by locus in each sample is shown in Table 2.

Table 1 - Enzyme systems, number of loci assayed (number of polymorphic loci in parentheses), and the respective buffers in which electrophoretic analyses were conducted in Digelasinus diversipes.

\begin{tabular}{lcl}
\hline Enzymatic systems & $\begin{array}{c}\text { Loci analyzed total } \\
\text { (Polymorphic) }\end{array}$ & Buffer \\
\hline$\beta$-Hydroxybutyrate dehydrogenase - $\beta$-Hbdh & $1(0)$ & $\mathrm{C}$ \\
Fumarase - Fum & $1(0)$ & $\mathrm{C}$ \\
Mannose - 6 - phosphate isomerase - Mpi & $1(1)$ & $\mathrm{C}$ \\
Glucose - 6 - phosphate dehydrogenase - G6pd & $1(0)$ & $\mathrm{C}$ \\
$\alpha$-Glycerophosphate dehydrogenase - $\alpha$-Gpdh & $3(2)$ & $\mathrm{C}$ \\
6-Phosphogluconate dehydrogenase - 6Pgd & $1(0)$ & $\mathrm{D}$ \\
Isocitrate dehydrogenase - Icd & $1(1)$ & $\mathrm{D}$ \\
Malate dehydrogenase - Mdh & $3(1)$ & $\mathrm{D}$ \\
Superoxide dismutase - Sod & $2(1)$ & $\mathrm{E}$ \\
Esterases - Est & $6(4)$ & $\mathrm{A}$ \\
Acid phosphatases - Acp & $3(2)$ & $\mathrm{A}$ \\
Leucil Aminopeptidase - Lap & $1(0)$ & $\mathrm{A}$ \\
Peptidases - Pep & $3(3)$ & $\mathrm{B}$ \\
Diaphorases - Dia & $2(0)$ & $\mathrm{B}$ \\
Aconitase - Acon & $1(0)$ & $\mathrm{A}$ \\
Phosphoglucoseisomerase - Gpi & $1(0)$ & $\mathrm{A}$ \\
Phosphoglucomutase - Pgm & $1(1)$ & $\mathrm{C}$ \\
Hexokinase - Hk & $1(0)$ & $\mathrm{C}$ \\
Arginine kinase - ArgK & $1(0)$ & $\mathrm{E}$ \\
Glutamic - oxaloacetic transaminase - Got & $1(0)$ & $\mathrm{B}$ \\
Pyruvate kinase - Pk & $1(0)$ & $1(0)$ \\
Aldolase - Ald & $1(0)$ & \\
Adenylate kinase - Ak & & $\mathrm{C}$ \\
\hline
\end{tabular}

A - Tris-citrate $\mathrm{pH}$ 7.5. B - Tris-citrate-borate $\mathrm{pH}$ 8.0-8.0. C - Tris-citrate $\mathrm{pH}$ 8.0. D - Tris-histidine $\mathrm{pH}$ 6.0-6.6. E - Tris-EDTA-maleate-magnesium $\mathrm{pH} 7.4$. 
Table 2 - Allele frequencies (standard deviations in parentheses), $\chi^{2}$ values of genetic equilibrium tests (and number of analyzed individuals in parentheses), proportion of polymorphic loci (P), mean number of alleles (A), and observed average heterozygosity $(\mathrm{H})$ in Digelasinus diversipes.

\begin{tabular}{|c|c|c|c|c|}
\hline Locus & Allele & Pat00 & Pat01 & Inf01 \\
\hline \multirow[t]{2}{*}{ Pep A } & 114 & $0.01( \pm 0.001)$ & $0.12( \pm 0.005)$ & $0.11( \pm 0.007)$ \\
\hline & 100 & 0.99 & 0.88 & 0.89 \\
\hline$\chi^{2}(\mathrm{n})$ & & $0.01(76)$ & $0.17(181)$ & $1.71(107)$ \\
\hline \multirow[t]{2}{*}{ Pep B } & 106 & & $0.39( \pm 0.016)$ & $0.30( \pm 0.023)$ \\
\hline & 100 & & 0.61 & 0.70 \\
\hline$\chi^{2}(\mathrm{n})$ & & & $18.62 *(126)$ & $10.91 *(108)$ \\
\hline \multirow[t]{2}{*}{ Pep D } & 100 & & $0.62( \pm 0.015)$ & $0.55( \pm 0.014)$ \\
\hline & 88 & & 0.38 & 0.45 \\
\hline$\chi^{2}(\mathrm{n})$ & & & $6.34 *(109)$ & $1.07(54)$ \\
\hline \multirow[t]{2}{*}{ Acp 1} & 114 & $0.07( \pm 0.007)$ & $0.20( \pm 0.009)$ & $0.26( \pm 0.013)$ \\
\hline & 100 & 0.93 & 0.80 & 0.74 \\
\hline$\chi^{2}(\mathrm{n})$ & & $0.24(43)$ & $7.39 *(157)$ & $0.54(98)$ \\
\hline \multirow[t]{2}{*}{ Acp 2} & 100 & $0.91( \pm 0.009)$ & $0.67( \pm 0.012)$ & $0.64( \pm 0.016)$ \\
\hline & 80 & 0.09 & 0.33 & 0.36 \\
\hline$\chi^{2}(\mathrm{n})$ & & $0.45(43)$ & $1.22(160)$ & $0.85(107)$ \\
\hline \multirow[t]{2}{*}{ Icd } & 133 & $0.18( \pm 0.012)$ & $0.15( \pm 0.007)$ & $0.07( \pm 0.005)$ \\
\hline & 100 & 0.82 & 0.85 & 0.93 \\
\hline$\chi^{2}(\mathrm{n})$ & & $1.45(76)$ & $1.14(182)$ & $0.69(108)$ \\
\hline \multirow[t]{3}{*}{ Mpi } & 100 & $0.55( \pm 0.024)$ & $0.44( \pm 0.013)$ & $0.60( \pm 0.016)$ \\
\hline & 86 & $0.27( \pm 0.020)$ & $0.40( \pm 0.013)$ & $0.12( \pm 0.007)$ \\
\hline & 93 & $0.18( \pm 0.014)$ & $0.17( \pm 0.007)$ & $0.28( \pm 0.014)$ \\
\hline$\chi^{2}(\mathrm{n})$ & & $3.85(51)$ & $0.72(169)$ & $1.57(106)$ \\
\hline \multirow[t]{2}{*}{ Est 1} & 106 & $0.01( \pm 0.0005)$ & $0.09( \pm 0.004)$ & $0.05( \pm 0.003)$ \\
\hline & 100 & 0.99 & 0.91 & 0.95 \\
\hline$\chi^{2}(\mathrm{n})$ & & $0.00(76)$ & $1.819(182)$ & $0.31(108)$ \\
\hline \multirow[t]{2}{*}{ Est 3} & 108 & $0.01( \pm 0.001)$ & 0.00 & 0.00 \\
\hline & 100 & 0.99 & 1.00 & 1.00 \\
\hline$\chi^{2}(\mathrm{n})$ & & $0.01(74)$ & 182 & 108 \\
\hline \multirow[t]{2}{*}{ Est 4} & 112 & $0.34( \pm 0.018)$ & $0.23( \pm 0.009)$ & $0.10( \pm 0.006)$ \\
\hline & 100 & 0.66 & 0.77 & 0.90 \\
\hline$\chi^{2}(\mathrm{n})$ & & $3.14(76)$ & $0.01(181)$ & $1.39(108)$ \\
\hline \multirow[t]{2}{*}{ Sod 1} & 100 & $0.93( \pm 0.005)$ & $0.85( \pm 0.007)$ & $0.42( \pm 0.016)$ \\
\hline & 87 & 0.07 & 0.15 & 0.58 \\
\hline$\chi^{2}(\mathrm{n})$ & & $0.46(76)$ & $0.02(1640$ & $2.27(108)$ \\
\hline \multirow[t]{2}{*}{ Pgm } & 112 & $0.20( \pm 0.013)$ & $0.37( \pm 0.012)$ & $0.49( \pm 0.017)$ \\
\hline & 100 & 0.80 & 0.63 & 0.51 \\
\hline$\chi^{2}(\mathrm{n})$ & & $1.67(76)$ & $0.11(179)$ & $7.25 *(108)$ \\
\hline \multirow[t]{3}{*}{ Mdh c } & 120 & $0.08( \pm 0.006)$ & $0.03( \pm 0.001)$ & $0.09( \pm 0.005)$ \\
\hline & 100 & 0.92 & 0.97 & $0.89( \pm 0.007)$ \\
\hline & $110+87$ & 0 & 0 & $0.02( \pm 0.001)$ \\
\hline$\chi^{2}(\mathrm{n})$ & & $15.88 *(76)$ & $0.14(182)$ & $1.12(108)$ \\
\hline $\mathrm{P}$ & & 0.34 & 0.34 & 0.31 \\
\hline A & & 1.4 & 1.4 & 1.6 \\
\hline $\mathrm{H}$ & & $0.05( \pm 0.018)$ & $0.01( \pm 0.027)$ & $0.10( \pm 0.028)$ \\
\hline
\end{tabular}

Gene frequencies were estimated by direct counting. Genetic equilibrium was estimated by an adherence test $(\alpha=5 \%)$, using observed and expected genotype frequencies. Genetic variation was estimated by intralocus heterozygosity and by expected and observed mean heterozygosity and the corresponding standard errors (Nei and Roychoudhury, 1974) for each sample and for the whole sample. Comparisons among heterozygosities were made utilizing the bootstrap over loci method (Efron, 1982), with 200 replications performed at a 95\% confidence interval, using Instat-3 software. Genetic differentiation among samples was established by Wright's F-statistics coefficients $\left(\mathrm{F}_{\mathrm{IS}}, \mathrm{F}_{\mathrm{ST}}\right.$, and $\left.\mathrm{F}_{\mathrm{IT}}\right)$, and by genetic distances according to Cavalli-Sforza and Edwards (1967) and Nei $(1972,1978)$, calculated using BYOSIS-1 software (Swofford and Selander, 1989). The mean relatedness among individuals from cocoon masses and the corresponding standard error were calculated using the Relatedness 4.2b software (Queller and Goodnight, 1989).

\section{Results}

Of the 38 enzyme loci assayed, 16 were polymorphic using the $1 \%$ criterion ( $42 \%$, see Table 2). Loci Est5, $\alpha G p d h 1$ and $\alpha G p d h 2$ were not included in our analyses, due to difficulties in phenotype identification, probably resulting from slight age differences among samples. The number of analyzed individuals for each locus and sample, the proportion of polymorphic loci $(\mathrm{P})$, the mean number of alleles per locus (A), allele frequencies, and $\chi^{2}$ values for genetic equilibrium are summarized in Table 2 . The data showed that locus $M d h$ is not in equilibrium at Pat00, similarly to loci PepB, PepD and Acp1 at Pat01, and loci PepB and $P g m$ at Inf01. Twenty-nine adult males from five cocoon masses were sampled, and no diploid males were detected.

The highest intra-locus heterozygosity $\left(\mathrm{H}_{\mathrm{i}}\right)$ values were observed for locus $M p i$ in the three samples $(0.41$, 0.65 , and 0.55 , in samples Pat00, Pat01, and Inf01, respectively), while the lowest values were observed for locus Est1 in Pat00 (0.013) and Inf01 (0.10), and for locus $M d h$ (0.055) in Pat01. The observed mean heterozygositys was $0.052 \pm 0.018$ in sample Pat00, $0.097 \pm 0.027$ in Pat01, and $0.101 \pm 0.028$ in Inf01. The average value of the observed mean heterozygositys $(\mathrm{H})$ was $0.094 \pm 0.025$.

The F-statistics values are shown in Table 3. A significant value of $\mathrm{F}_{\mathrm{ST}}\left(\mathrm{F}_{\mathrm{ST}}=0.070 ; \chi^{2}=458.9 ; \mathrm{p}<0.05\right)$ and a non-significant value of $\mathrm{F}_{\mathrm{IS}}\left(\mathrm{F}_{\mathrm{IS}}=0.062 ; \chi^{2}=29.9\right.$; $\mathrm{p}>0.05)$ were found. When the samples were analyzed pairwise, a significant value of $\mathrm{F}_{\mathrm{ST}}$ and a non-significant value of $\mathrm{F}_{\mathrm{IS}}$ were observed. Nei's genetic distance coefficient (1978) was 0.017 between Pat00 and Pat01, 0.065 between Pat00 and Inf01, and 0.041 between Pat01 and Inf01. 
Table 3 - F-statistics coefficients and the respective chi-squares determined by enzyme loci in Digelasinus diversipes.

\begin{tabular}{lccllcc}
\hline Locus & $\mathrm{F}_{\mathrm{ST}}$ & $\chi^{2}$ & $\mathrm{~F}_{\mathrm{IS}}$ & $\chi^{2}$ & $\mathrm{DF}$ & $\mathrm{F}_{\mathrm{IT}}$ \\
\hline PepA & 0.031 & $22.57^{*}$ & 0.045 & 0.74 & 2 & 0.013 \\
Acp1 & 0.028 & $19.99^{*}$ & 0.15 & $8.03^{*}$ & 2 & 0.174 \\
Acp2 & 0.076 & $47.12^{*}$ & 0.018 & 0.10 & 2 & 0.059 \\
Icd & 0.018 & $13.18^{*}$ & 0.046 & 0.77 & 2 & 0.028 \\
Mpi & 0.033 & $43.03^{*}$ & 0.087 & 2.47 & 4 & 0.117 \\
Est1 & 0.025 & $18.30^{*}$ & 0.079 & 2.28 & 2 & 0.052 \\
Est3 & 0.004 & 3.50 & 0.011 & 0.05 & 2 & 0.006 \\
Est4 & 0.053 & $38.69^{*}$ & 0.068 & 1.69 & 2 & 0.117 \\
Sod1 & 0.256 & $178.18^{*}$ & 0.062 & 1.34 & 2 & 0.302 \\
Pgm & 0.060 & $43.56^{*}$ & 0.147 & $7.84 *$ & 2 & 0.198 \\
Mdhc & 0.014 & $30.74^{*}$ & 0.111 & 4.51 & 6 & 0.124 \\
Mean & 0.070 & $458.9 *$ & 0.062 & 29.9 & 28 & 0.127 \\
\hline
\end{tabular}

$* \mathrm{p}<0.05$.

The mean relatedness coefficient was estimated at $0.36 \pm 0.15$ in sample Pat00, $0.23 \pm 0.09$ in Pat01, and $0.44 \pm 0.10$ in Inf01.

\section{Discussion}

A high genetic diversity (proportion of polymorphic loci, mean number of alleles per locus, and mean heterozygosity) was detected in the three samples of $D$. diversipes analyzed. For the purpose of comparing these data with those previously reported in the literature, Table 4 presents an average value of the mean heterozygosity for Hymenoptera (Metcalf et al., 1975; Wagner and Briscoe, 1983; Crespi, 1991; Owen et al., 1992; Shoemaker et al., 1992; and unpublished data of our laboratory) and for Symphyta (Graur, 1985; Sheppard and Heydon, 1986; Woods and Guttman, 1987; Rosenmeier and Packer, 1993; Boato and Battisti, 1996).
The mean heterozygosity values observed in our samples do not differ significantly from each other (bootstrap over locus, CI 95\%; Efron, 1982) and the value of the average heterozygosity in the $D$. diversipes population studied do not differ significantly from the mean heterozygosity reported for sawflies. However, this value differs significantly from those of other Hymenopteran species (bootstrap over locus, CI 95\%; Efron, 1982). A new average heterozygosity value for sawflies, including our $\mathrm{H}$ value for $D$. diversipes $(0.086 \pm 0.054)$, differs significantly from previous estimates for Hymenopterans (Mann-Whitney's U test - one-tailed).

The low levels of genetic variability found in Hymenoptera are justified by haplodiploidy and sociality, associated with the effective population size. However, the effective population size is also influenced by the sex ratio (Crozier, 1976; Hedrick and Parker, 1997) and by the mating system (Berkelhamer, 1983; Owen, 1985), and the levels of heterozygosity have been found to be distinct among species of the same social level (Owen, 1985). Data presented here show high levels of heterozygosity in Symphyta, as found by Sheppard and Heydon (1986), Rosenmeier and Packer (1993), and Boato and Battisti (1996). These data suggest that haplodiploidy per se does not seem to be responsible for the low levels of genetic variability in Hymenoptera.

The F-statistics values show that the three samples are not genetically homogeneous, suggesting a subdivided population. The samples collected in two successive years at Lake Pato (Pat00 e Pat01) are also genetically heterogeneous. These findings could be justified by a heterogeneous spatial sampling inside the Pato Lake area where the cocoon masses were collected.

The $\mathrm{F}_{\mathrm{IS}}$ values for all loci but two revealed that there were no significant levels of inbreeding either within samples or in the whole sample. The absence of diploid males validates this result. Based on the number of males analyzed and considering the probability of a diploid male be-

Table 4 - Genetic data used in the analyses of this work.

\begin{tabular}{lccccc}
\hline Species & Number of loci analyzed & $\mathrm{P}^{\mathrm{a}}$ & $\mathrm{A}^{\mathrm{b}}$ & $\mathrm{H}^{\mathrm{c}}$ & References \\
\hline Euura s-nodus & 17 & 47 & 1.76 & 0.137 & Sheppard and Heydon, 1986 \\
Euura & 17 & 47 & 1.65 & 0.124 & Sheppard and Heydon, 1986 \\
Schizocerella pilicornis & 16 & 38 & 1.75 & 0.166 & Sheppard and Heydon, 1986 \\
Diprion similis & 15 & 8.7 & 1.1 & $0.032( \pm 0.023)$ & Woods and Guttman, 1987 \\
Neodiprion ssp (7 species) & 15 & 8.7 & 1.2 & $0.051( \pm 0.028)$ & Woods and Guttman, 1987 \\
Neodiprion ssp (3 species) & 45 & 28.9 & 1.25 & 0.048 & Rosenmeier and Packer, 1993 \\
Cephalcia ssp (7 species) & 28 & & 1.76 & $0.197(0.064)$ & Boato and Battisti, 1996 \\
Digelasinus diversipes & 38 & 42 & 1.43 & $0.094(0.025)$ & present work \\
Symphyta & & & & $0.0756(0.0011)$ & literature data* \\
Hymenoptera & & & & $0.0342( \pm 0.0002)$ & literature data* \\
\hline
\end{tabular}

a proportion of polymorphic loci. ${ }^{b}$ mean number of alleles per locus. ${ }^{c}$ average heterozigosity. ${ }^{*}$ references cited in Discussion. 
ing heterozygous for at least one of the genetic markers assayed, the diploid male frequency in this species could anyway not have exceeded 3\%. Although the possibility of eliminatory mechanisms at a larval stage of the diploid males produced cannot be ruled out, this data is in accordance with the absence of inbreeding detected by the $\mathrm{F}_{\text {IS }} \mathrm{co}-$ efficient of each sample and of the whole sample. In agreement with the complementary sex determination (CSD) model in Hymenoptera (Cook, 1993), inbreeding leads to homozygosity of sexual alleles and, as a consequence, to diploid males. If this mechanism is responsible for sex determination in Digelasinus diversipes, then the absence of diploid males is likely to reflect the low frequency of sibmatings in this species.

Genetic relatedness among adult females of cocoon masses was low, suggesting that during feeding behavior larvae from different ovipositions associated to form the cocoon masses. Although this result could also be explained by the mating of one female with several males, this does not seem to be the case. Females mating only once have been reported in the literature (Östrand and Anderbrant, 2001), even in Neotropical Symphyta species (Dias, 1976). Our field observations of $D$. diversipes behavior (Boraschi et al., in preparation) corroborate the above mentioned idea. These low levels of genetic relatedness suggest that such an associative behavior can occur even among larvae of neighbouring trees.

Populational inbreeding levels are correlated with larval and adult dispersal ability and with the mean relatedness of the individuals inside the cocoon mass. Although dispersal behavior has been poorly studied, adult sawflies are known as weak-flyers (Mopper et al., 1990; Smith, 1993; Gauld and Bolton, 1996; Östrand and Anderbrant, 2001). According to Östrand and Anderbrant (2001), the females of Neodiprion sertifer disperse before or after mating and, although it is difficult to observe dispersion over distances greater than $5 \mathrm{~m}$, an adult sawfly usually disperses less than $1 \mathrm{~m}$. In contrast, the gregarious behavior of sawfly larvae encompasses many families (Heitland and Pschorn-Walcher, 1993), and, during larval foraging, a group can exhibit fragmentation or coalescence with other groups (Costa and Louque, 2001). Furthermore, according to Craig and Mopper (1993), dispersal at the larval stage is very high (these authors pointed out 6 of 10 species with high larval dispersal ratio).

In the Neotropical species Themos olfensii (Dias, 1975) and Dielocerus diasii (Dias, 1976), larvae exhibit gregarious behavior, and the feeding groups may or may not coalesce. Cocoon masses of $D$. diasii are formed by a very high number of individuals from larval groups oviposited by more than one female.

In Digelasinus diversipes, the larvae also exhibit a gregarious behavior. The genetic data presented here bring evidence suggesting that these groups disperse during feeding behavior and that they associate within a communal construction of cocoon masses. The population studied here was subdivided, with absent or low gene flow among the samples, indicating that $D$. diversipes is a species with limited dispersion ability, which is in agreement with previously published data on other Symphyta.

Due to their evolutionary importance for Hymenoptera and to some biological similarities with other insects, further studies are necessary to better understand the population genetic structure and the sociogenetic structure of the cocoon masses of sawflies.

\section{Acknowledgments}

We thank Rui Carlos Peruquetti, Isabel Cristina de Godoy, Horácio Gomes and Luis Henrique da Silva for helping with sample collection and technical support; Henri Lorenzi from the "Instituto Plantarum", Nova Odessa, for the identification of Eugenia glazioviana; David R. Smith for the identification of Digelasinus diversipes; and CAPES for financial support.

\section{References}

Berkelhamer RC (1983) Intraspecific genetic variation and haplodiploidy, eusociality, and polygyny in the Hymenoptera. Evolution 37:540-545.

Boato A and Battisti A (1996) High genetic variability despite haplodiploidy in primitive sawflies of the genus Cephalcia (Hymenoptera, Pampilidae). Experientia 52:516-521.

Cavalli-Sforza LL and Edwards AWF (1967) Phylogenetic analysis: models and estimation procedures. Evolution 21:550570.

Cook JM (1993) Sex determination in the Hymenoptera: A review of models and evidence. Heredity 71:421-435.

Costa JT and Louque RW (2001) Group foraging and trail following behavior of the Red-headed pine sawfly Neodiprion lecontei (Fitch) (Hymenoptera: Symphyta: Diprionidae). Ann Entomol Soc Am 94:480-489.

Craig TP and Mopper S (1993) Sex variation in sawflies. In: Wagner M and Raffa KF (eds) Sawfly Life History Adaptations to Woody Plants. Academic Press, New York, pp 61-93.

Crespi BJ (1991) Heterozygosity in the haplodiploid Thysanoptera. Evolution 45:458-464.

Crozier RH (1976) Counter-intuitive property of effective population size. Nature 262:384.

Dias BFS (1975) Comportamento pré-social de sínfitas do Brasil Central. I. Themos olfensii (Klug) (Hym., Argidae). Studia Ent 18:401-432.

Dias BFS (1976) Comportamento pré-social de sínfitas do Brasil Central. I. Dielocerus diasii Smith, 1975 (Hym., Argidae). Studia Ent 19:461-501.

Efron B (1982) The Jacknife, the Bootstrap and other resampling plans. CBMS-NSF Regional Conference Series in Applied Mathematics, Monograph 38, SIAM, Philadelphia.

Gauld I and Bolton B (1996) The Hymenoptera. 2nd ed. Oxford University Press, London, 839 pp.

Graur D (1985) Gene diversity in Hymenoptera. Evolution 39:190-199. 
Hedrick PW and Parker JD (1997) Evolutionary genetics and genetic variation of haplodiploids and $\mathrm{x}$-linked genes. Annu Rev Ecol Syst 28:55-83.

Heitland W and Pschorn-Walcher H (1993) Feeding strategies of sawflies. In: Wagner M and Raffa KF (eds) Sawfly Life History Adaptations to Woody Plants. Academic Press, New York, pp 94-118.

Lester LJ and Selander RK (1979) Population genetics of haplodiploid insects. Genetics 92:1329-1345.

Metcalf RA, Marlin JC and Whitt GS (1975) Low levels of genetic heterozygosity in Hymenoptera. Nature 257:792-794.

Mopper S, Craig TG and Price PT (1990) Plant phenotype and interspecific competition between insects determine sawfly performance and density. Ecology 71:2135-2144.

Nei M (1972) Genetic distance between populations. Am Nat 106:282-292.

Nei M (1978) Estimation of average heterozygosity and genetic distance from a small number of individuals. Genetics 89:580-590.

Nei M and Roychoudhury AK (1974) Sampling variances of heterozygosity and genetic distance. Genetics 76:379-390.

Östrand F and Anderbrant O (2001) Mating duration and frequency in a pine sawfly. J Insect Behav 14:595-606.

Owen RE (1985) Difficulties with the interpretation of patterns of genetic variation in the eusocial Hymenoptera. Evolution 39:201-205.

Owen RE, Mydynski JL, Packer L and McCorquodale DB (1992) Allozyme variation in bumble bees (Hymenoptera: Apidae). Biochem Genet 30:443-453.

Pamilo P, Varvio-Aho SL and Pekkarinen A (1978) Low enzyme gene variability in Hymenoptera as a consequence of haplodiploidy. Hereditas 88:93-99.

Penteado-Dias AM (1991) Himenópteros parasitóides associados a ninhos de Digelasinus diversipes (Kirby, 1882) (Hymenoptera, Argidae). Revta bras Ent 35:545-548.

Queller DC and Goodnight KF (1989) Estimating relatedness using genetic markers. Evolution 43(2):258-275.
Rosenmeier L and Packer L (1993) A comparison of genetic variation in two sibling species pairs of haplodiploid insects. Biochem Genet 31:185-200.

Sheppard WS and Heydon SL (1986) High levels of genetic variability in three male-haploid species. Evolution 40:13501353.

Shoemaker DD, Costa JT and Kenneth GR (1992) Estimates of heterozygosity in two social insects using a large number of electrophoretic markers. Heredity 69:573-582.

Smith DR (1992) A synopsis of the sawflies (Hymenoptera: Symphyta) of America south of the United States: Argidae. Mem Am Entomol Soc 39, 201 pp.

Smith DR (1993) Systematics, life history, and distribution of sawflies. In: Wagner M and Raffa KF (eds) Sawfly Life History Adaptations to Woody Plants. Academic Press, New York, pp 3-32.

Smithies O (1955) On electrophoresis in starch gels: group variation in the serum proteins of normal human adults. Biochem J 61:620-641.

Snyder TP (1975) Lack of allozymic variability in three bee species. Evolution 28:687-689.

Swofford DL and Selander RB (1989) Biosys-1. A computer program for the analysis of allelic variation in population genetics and biochemical systematics. Release 1.7. Swofford, DL, Illinois Nat. Hist. Survey, 43 pp.

Van Valen L (1965) Morphological variation and width of ecological niche. Am Nat 99:377-390.

Wagner AE and Briscoe DA (1983) An absence of enzyme variability within two species of Trigona (Hymenoptera). Heredity 50:97-103.

Woods PE and Guttman SI (1987) Genetic variation in Neodiprion (Hymenoptera: Symphyta: Diprionidae) sawflies and a comment on low levels of genetic diversity within the Hymenoptera. Ann Entomol Soc Am 80:590-599.

Associate Editor: Louis Bernard Klaczko 